\title{
Dissociations among memory measures in memory-impaired subjects: Evidence for a processing account of memory
}

\author{
TERESA A. BLAXTON \\ National Institute of Neurological Disorders and Stroke, Bethesda, Maryland
}

\begin{abstract}
Deficits in conceptual transfer on both implicit and explicit memory tests were obtained for memory-impaired temporal lobe epileptic (TLE) subjects in three studies. In Experiment 1, in which a generate-read paradigm was employed, memory-impaired TLEs failed to show normal generation effects on conceptually driven tests of semantic cued recall and general knowledge questions, although their data-driven memory as measured by word-fragment completion and graphemic cued recall tasks was normal. In Experiment 2, memory-impaired patients having left temporal lobe seizure foci were tested on these four tasks and compared with nonimpaired TLEs having right temporal foci. The left TLEs showed deficits on conceptually driven tasks and normal memory for data-driven tests. These findings were extended in Experiment 3, in which left TLE patients failed to show any benefit from blocked study, as compared with random study, on category production and semantic cued-recall tests, although right TLEs and normal controls showed blocking effects on both tasks. These findings may be accommodated by a processing framework of memory in which memory-impaired patients are characterized as having deficits in conceptual, but not in data-driven, processing capabilities.
\end{abstract}

A class of experimental result that has become almost commonplace in recent years is one in which performance on two or more memory tasks is shown to be uncorrelated or dissociated even though study conditions are held constant across tasks (see Richardson-Klavehn \& Bjork, 1988, and Schacter, 1987, for reviews). Jacoby (1983) reported a rather dramatic example of a dissociation, in which a study manipulation was shown to produce opposite effects on recognition and perceptual identification performance. A generation effect was observed for yes/no recognition, in which items generated at study were recognized more often than were items read in the absence of semantic context. However, this generation effect was actually reversed on a task of perceptual identification in which subjects attempted to read words following very brief presentations. Subjects were better able to identify items previously studied without semantic context than they were able to identify targets generated from antonym cues during study. With the ensuing proliferation of similar demonstrations, memory researchers have become increasingly interested in offering theoretical accounts of such experimental findings.

The author would like to thank William Theodore and Paul Fedio for providing access to patients and experimental resources. Appreciation is also expressed to Roddy Roediger, Endel Tulving, Shahin Hashtroudi, and Barbara Schwartz for helpful comments on an earlier version of the paper. Finally, thanks are given to Dan Schacter, Larry Jacoby, and two anonymous reviewers for helpful suggestions for revision. Correspondence concerning this article should be addressed to T. A. Blaxton at National Institutes of Health, Building 10, Room 5C205, Bethesda, MD 20892.
One theory advanced to explain dissociations derives from the transfer appropriate processing principle introduced by Morris, Bransford, and Franks (1977). This principle holds that memory will be improved to the degree that the type of processing engaged at study overlaps with that required to perform a subsequent memory task. Dissociations among various memory measures are obtained when processing requirements of the tests differ, resulting in varying degrees of match or transfer between the type of processing performed at study and test. As originally suggested by Jacoby (1983), one may distinguish between conceptually driven processing, which involves the analysis of meaning, and data-driven processing, which entails analysis of physical characteristics or surface information. By this account, the conceptual processing engaged when subjects generate rather than read items during study transfers well to the conceptually driven recognition test. Conversely, the data-driven processing evoked when reading words in the absence of semantic context during study, as opposed to generating them from conceptual cues, transfers well to the datadriven test of perceptual identification.

There is now substantial experimental evidence that the processing account of memory successfully predicts many patterns of dissociations among memory measures in normal subjects (e.g., Blaxton, 1989, 1992; Roediger \& Blaxton, 1987a, 1987b; Roediger, Srinivas, \& Weldon, 1989; Roediger, Weldon, \& Challis, 1989; Srinivas \& Roediger, 1990; Weldon \& Roediger, 1987). The theory's utility, however, has yet to be established in one important domain-namely, that of memory function in patients with neurological damage (see Roediger, 1990). The purpose 
of the present set of experiments was to assess the utility of the processing account in accommodating patterns of dissociations among memory measures obtained for a group of memory-impaired patients with temporal lobe damage.

Dissociations among memory measures are commonly observed for various memory-impaired subject groups (e.g., Mayes, Meudell, \& Pickering, 1985; Wood, Ebert, \& Kinsbourne, 1982), and, in fact, it was the discovery of preserved learning for some tasks in amnesic subjects that served as a catalyst for the current interest in this topic within the realm of normal memory function. In one of the most noted of these demonstrations, Warrington and Weiskrantz (1970, Experiment 2) presented amnesic and matched control subjects with a list of five-letter words three times prior to testing them on either free recall, recognition, word-stem completion, or word-fragment identification in which letters of individual words had been visually degraded. Results showed that although recall and recognition performance for amnesics was inferior to that of controls, amnesics did show evidence of learning, in that the two groups were equally likely to produce previously studied items on both the stem-completion and the partial-word-identification tasks. Numerous similar findings have been reported with a variety of tasks (see Shimamura, 1986, for a review), and several theories have been proposed to account for these findings with patient groups (e.g., Cohen, 1984; Poulos \& Wilkinson, 1984; Schacter, 1991; Squire, 1987; Tulving \& Schacter, 1990).

With regard to the Warrington and Weiskrantz (1970) study, one could argue that a processing framework of memory can account for the pattern of dissociations obtained. The assumption is that amnesics are impaired on conceptually driven tests, but not on tests with data-driven processing requirements. Thus, the amnesics were impaired on conceptually driven tests of free recall and recognition memory, although their performance on more data-driven measures of partial-word identification and word-stem completion was normal. Indeed, this account describes results from several other experiments in which amnesic patients have been shown to be impaired on conceptually driven tasks, but not on data-driven memory tasks. To illustrate, impairments on such conceptually driven tasks as free recall, cued recall, and recognition have been shown in amnesic subjects in conjunction with intact performance on tasks having data-driven processing requirements such as word identification (Cermak, Talbot, Chandler, \& Wolbarst, 1985; Nissen, Cohen, \& Corkin, 1981), picture identification (Warrington \& Weiskrantz, 1968), speeded reading (Moscovitch, 1984), rating unfamiliar melodies (Johnson, Kim, \& Risse, 1985), and word-stem completion (e.g., Graf, Shimamura, \& Squire, 1985; Graf, Squire, \& Mandler, 1984; Schacter, 1985; Schacter \& Graf, 1986a, 1986b; Shimamura \& Squire, 1984; Squire, Wetzel, \& Slater, 1978). This characterization of memory deficits as being due to impairments in conceptual processing is similar to arguments made previously by other memory theorists. For exam- ple, Cermak and his colleagues have reported in a series of studies that amnesic Korsakoffs tend to encode only shallow or perceptual features of to-be-remembered information rather than deeper semantic features (e.g., Cermak, 1989; Cermak \& Butters, 1972; Cermak, Butters, \& Gerrein, 1973; Cermak, Butters, \& Moreines, 1974; Cermak, Naus, \& Reale, 1976).

The most serious problem for these processing accounts of memory deficits is that there are other experiments testing amnesic subjects that show intact performance on tests that are more conceptually driven (e.g., Gardner, Boller, Moreines, \& Butters, 1973; McAndrews, Glisky, \& Schacter, 1987). For example, Graf et al. (1985, Experiment 2) reported that amnesic subjects showed as much transfer as did healthy and alcoholic controls on a conceptually driven test of word production given category labels as cues. Thus, it appears that the evidence from neurologically impaired subject groups has been somewhat mixed, with some patient groups showing impaired performance on conceptually driven tasks and others showing no deficits.

One key question is why some of these experiments show intact conceptual transfer in patient groups, whereas others do not. One possibility derives from the choice of memory tasks used across experiments. In cases showing conceptual processing deficits, most of the tasks have been explicit memory tests, such as recognition and recall. These tests may be contrasted with implicit tests, such as category production, for which intact transfer has been observed. Since the processing account predicts that conceptual transfer should be impaired in these patient groups regardless of the implicit or explicit nature of the memory task, this question bears scrutiny.

Another factor that is likely mediating patterns of results is the variation in brain damage across amnesic subject groups. Many experiments have included amnesic patients of mixed etiologies (e.g., Graf \& Schacter, 1985; McAndrews et al., 1987), and so it is difficult to ascertain which brain lesions might be contributing to poor memory performance. However, in cases in which patient etiologies are more uniform within groups, many of the amnesic patients tested suffer from Korsakoff's syndrome (e.g., Graf et al., 1985), a disorder characterized by damage to the frontal lobes and dorsothalamic nuclei. A question arises, then, as to what patterns of results might obtain from a group of memory-impaired subjects having neurological damage to other brain regions, such as temporal lobe structures that are known to be important to memory function.

The present set of experiments was designed to explore these questions (1) by examining performance on several conceptually driven and data-driven memory tasks having both implicit and explicit retrieval requirements and (2) by testing a group of memory-impaired subjects having well-characterized temporal lobe lesions. Findings of intact performance on data-driven tasks along with impairments on conceptually driven tasks may be construed as support for the processing account. However, findings 
of either impaired data-driven test performance or intact conceptually driven performance would be problematic for the theory.

\section{EXPERIMENT 1}

In an experiment reported previously as a test of the processing account of memory, normal subjects studied words in three conditions prior to performing one of five memory tasks (see Blaxton, 1989, Experiment 1). In the no-context condition, subjects saw a neutral prime (XXX) prior to reading a target word aloud (e.g., "universe"). In the context condition, targets were read aloud following the presentation of a semantically related prime (e.g., GALAXY). Finally, in the generate condition, subjects produced the target themselves given a synonym and singleletter cue (e.g., GALAXY-U). Better performance was observed in the generate condition than in the no-context condition on conceptually driven tests of free recall, semantic cued recall, and a task of answering general knowledge questions. However, this generation effect was reversed for data-driven word-fragment completion and graphemic cued-recall tasks, which showed more transfer from the no-context study condition than from the generate study condition. Thus, tasks were dissociated according to the type of processing they required. This general pattern of results was obtained in two further experiments employing study manipulations of modality, typography, and imagery instruction.

The procedures reported earlier in Blaxton (1989, Experiment 1) were modified slightly in this experiment, in which performance of normal controls was compared with that of memory-impaired subjects. The modifications included the following: (1) both study condition and type of test were manipulated as within-subject factors, (2) the context study condition was dropped, (3) no free-recall test was included, and (4) the materials were changed slightly. As already discussed, the processing account predicts that patterns of transfer between study and test for the memory-impaired subjects should be much like that of normal controls on data-driven tasks of wordfragment completion and graphemic cued recall. They should show deficits in conceptual transfer, on the other hand, on the conceptually driven tasks of semantic cued recall and answering general knowledge questions.

\section{Method}

Subjects. Two groups of subjects were tested in Experiment 1. The first was a group of 16 memory-impaired patients diagnosed with intractable temporal lobe epilepsy (TLE). Seven of these subjects had previously had temporal lobectomies, and 9 had been admitted to NIH as surgical candidates for the temporal lobectomy procedure. All of the patients had mesial and lateral TL seizure foci as confirmed by surface and/or subdural electroencephalography (EEG). Additional lateralizing information was available from magnetic resonance (MR) and positron emission tomography (PET) scans for some patients. Seven females and 9 males were included in the group. These patients had a mean age of 33.4 years (range 26-46 years) and had received an average of 14.2 years of formal education (range 12-18 years). WAIS-R scores for the TLEs indicated that they were of average intelligence, with an overall mean of 97.4 (range 84-115).

Contrasted with their normal IQ scores, however, these patients were classified as being memory impaired on the basis of extremely low scores on two subtests of the Wechsler Memory Scale-Revised (WMS-R). Previous research has shown that the Logical Memory $I$ and Logical Memory II subtests are the best WMS-R predictors of verbal memory performance (Bornstein \& Chelune, 1988). These subtests require immediate and delayed recall of auditorily presented narrative passages. The patients in this experiment were only able to recall an average of 20 out of 44 possible concepts immediately following presentation (24th percentile of normal performance; range 2 nd -49 th percentile) and only 12 concepts after a 30 -min delay (14th percentile; range 7th-31st percentile). Thus, the TLE subjects exhibited severe verbal memory deficits even though their overall $\operatorname{cog}$ nitive functioning remained intact.

A group of 16 normal subjects similar to the TLE patients in terms of sex, age, and years of education was also tested. This group included 7 females and 9 males having an average age of 32.9 years (range 27-50 years) and an average education level of 14.1 years (range 12-16 years).

Memory tests and study materials. Four different types of memory tasks were employed in the experiment. All of these tasks were constructed such that half of the test items corresponded to previously studied words and half corresponded to new words. The first test was a word-fragment completion task in which the subjects tried to fill in the missing letters in order to form complete words (e.g., _UT_E__FL_ for "butterfly"). The second was a test of general knowledge in which subjects were given questions such as, "What kind of insect are the Monarch and the Queen Alexandra?" (answer "butterfly"). Both the word-fragment completion task and the general knowledge questions were implicit tests that could be completed without reference to the original study episode (see Graf \& Schacter, 1985). Two explicit cued-recall tests were also employed. One of these was a semantic cued-recall test in which the subjects were provided with words that were semantically related to previously studied items (e.g., MOTH as a cue for "butterfly"). The graphemic cued-recall test consisted of cue words that were physically or graphemically (but not semantically) similar to previously studied items (e.g., BUTTERY as a cue for "butterfly").

A set of 128 stimulus words were developed for use in the experiment. For each item, a word fragment, general knowledge question, semantic cue, and graphemic cue were constructed so that each item could be tested on all of the memory tasks described above. About half of these were drawn from the set of materials used by Blaxton (1989) and modified slightly for use with the patient population. The rest were developed specifically for this experiment. All modified and new items were tested with pilot subjects. (A full listing of materials is available from the author upon request.)

Design and counterbalancing. Type of memory task was manipulated as a within-subject variable in the experiment. The order in which the memory tests were administered to the subjects was determined using a balanced Latin square. Four orders of the tests were employed such that, across subjects, each test appeared in each position within an experimental session. This was done to control for any strategies that the subjects might develop during the course of the test session as a function of having already seen a particular type of test.

The memory materials were divided into two 64-item base lists. Each subject studied items from one of these base lists and was tested on those items in addition to the nonstudied items from the other base list. Thus, the subjects studying different base lists received the same form of a test, with half of the test items corresponding to studied items for half of the subjects and those same test items corresponding to nonstudied items for the other subjects. Across 
subjects, each item was presented equally often in both the studied and the nonstudied conditions in each test. Within a base list, items were further divided into four 16 -item sublists. The subjects studied one sublist at a time, and this study was immediately followed by a memory test. Items within a base list were always presented in the same order for study, and the memory tests were rotated through such that, across subjects, all items were tested equally often on all of the memory tasks.

Study condition was also manipulated as a within-subject variable. Within each sublist of 16 items, the subjects studied 8 items in the no-context condition and 8 items in the generate condition. In the no-context condition, each item was preceded by a neutral stimulus (e.g., XXX, BUTTERFLY). In the generate condition, the subjects generated target items given a semantically related word and the target's first letter (e.g., DRAGonfLY, B-). (Note that the semantically related cues used during study were different from those presented on the semantic cued-recall test.) The order of presentation for the two study conditions was counterbalanced across subjects, such that half of the subjects received the no-context condition prior to the generate condition for a given memory test and half received the opposite order. Across subjects, then, each item was presented equally often in each study condition.

For any particular subject, the order in which these study conditions were encountered in the session was alternated as well. That is, the no-context condition preceded the generate condition for two of the memory tasks (either the first and third tests or the second and fourth tests), but the reverse order of study conditions was presented for the other two tests. The manipulations just described resulted in a 2 (type of subject: TLEs vs. normal controls) $\times 3$ (study condition: no context, generate, nonstudied) $\times 4$ (type of memory task: word-fragment completion, general-knowledge questions, semantic cued recall, graphemic cued recall) mixed factor design.

Procedure. The subjects were tested individually. They were told that the experimental session would consist of a series of memory and language tasks. They were instructed that all of the tasks would be very different from one another, but the exact nature of the tests was left unspecified. Prior to studying items in the no-context condition, the subjects were told that they would be reading words aloud as they were presented on index cards and that alternating with these words there would be cards with the stimulus "XXX" printed on them. Before studying items in the generate condition, the subjects were told that they would be presented with alternating words and single letters. They were instructed to read the words silently and to generate associates aloud to the single letters (e.g., read "DRAGONFLY" silently and generate "BUTTERFLY" aloud as a response to the single letter " $b$ "). The subjects were given several examples with this procedure before studying words in the generate condition.

Both primes and targets were presented on index cards for $5 \mathrm{sec}$ each during study. The subjects read targets aloud in the no-context condition and generated targets aloud in the generate condition. In cases in which the subjects generated an unexpected response or were unable to generate any response in the 5-sec interval, the experimenter said the target aloud to the subject before proceeding.

Approximately $5 \mathrm{~min}$ following each study phase, the subjects received one of the four memory tasks. When administering any of these tests, the experimenter provided each subject with examples of how the test was to be completed and answered questions. Tests were constructed in booklets such that only one test item appeared on each page. The subjects were allowed to proceed through these tests at their own pace, with the restriction that they not spend more than $30 \mathrm{sec}$ on any one item.

For the word-fragment completion test, the subjects were told to fill in the missing letters in the fragments to form complete words and were informed that each fragment had only one solution. For the general knowledge task, the subjects were told that each question had a one-word answer and that this answer would never be included in the wording of the question. The experimenter never alluded to the previously studied items when giving instructions for either of these tasks. For the occasional subject who asked about the relation between studied items and the test, the experimenter explained that the test should be performed without referring to the study phase.

For the semantic cued-recall test, the experimenter explained that the words presented on the test were related in meaning to the studied items and that the subjects were to use these words as cues or reminders to help them remember words that had been presented during study. Prior to receiving the graphemic cued-recall test, the experimenter explained that the cues were similar in their physical construction to previously studied words but bore no relation to studied items in terms of meaning. For both cued-recall tests, the subjects were advised that the cues corresponded to words that the subjects had said aloud (or words that had been said aloud by the experimenter when the subjects failed to generate intended items in the generate condition).

In order to assess guessing rates on the cued-recall tests, equal numbers of cues corresponding to studied and nonstudied items were included. The subjects were informed of this prior to taking the tests. The subjects were instructed to first try and use each cue as a reminder for a previously studied item when completing the tests. They were further told that they were permitted to make guesses or to write down nonstudied items for cues that failed to remind them of studied words. This entire procedure lasted approximately $70 \mathrm{~min}$ for the normal controls and $90 \mathrm{~min}$ for the patient group, who tended to spend a longer time completing the memory tasks.

\section{Results and Discussion}

Prior to the overall statistical analyses, preliminary analyses were conducted to determine whether there were any effects of test order on the patterns of observed memory performance. Specifically, analyses of variance (ANOVAs) were conducted for each memory test including test order as a factor. There were four levels of test order corresponding to the four orders used across subjects. None of these analyses revealed main effects of test order, and this variable did not interact significantly with any other experimental variable. Because of these findings, test order was not included as a variable in the analyses reported for this experiment.

Analyses performed on the data were of two types. First an ANOVA was performed comparing proportion correct data from studied and nonstudied conditions. A second ANOVA included data from only the no-context and generate study conditions. Each analysis included data from both subject groups for two of the memory tests, either the two conceptually driven or the two data-driven tests. Post hoc comparisons assessing differences between individual cells were examined using least significant difference $(L S D)$ tests. All significance levels were set at $p<.05$, unless otherwise noted.

Conceptually driven memory tasks. Results from the general knowledge and semantic cued-recall tests are presented in Figure 1. An ANOVA including data from both studied and nonstudied conditions revealed a main effect of study $\left[F(2,180)=35.65, M S_{\mathrm{e}}=1.41\right]$. This reflected the fact that performance in the studied conditions was generally higher than that of the nonstudied conditions. Post hoc tests revealed that for the normal controls, bet- 


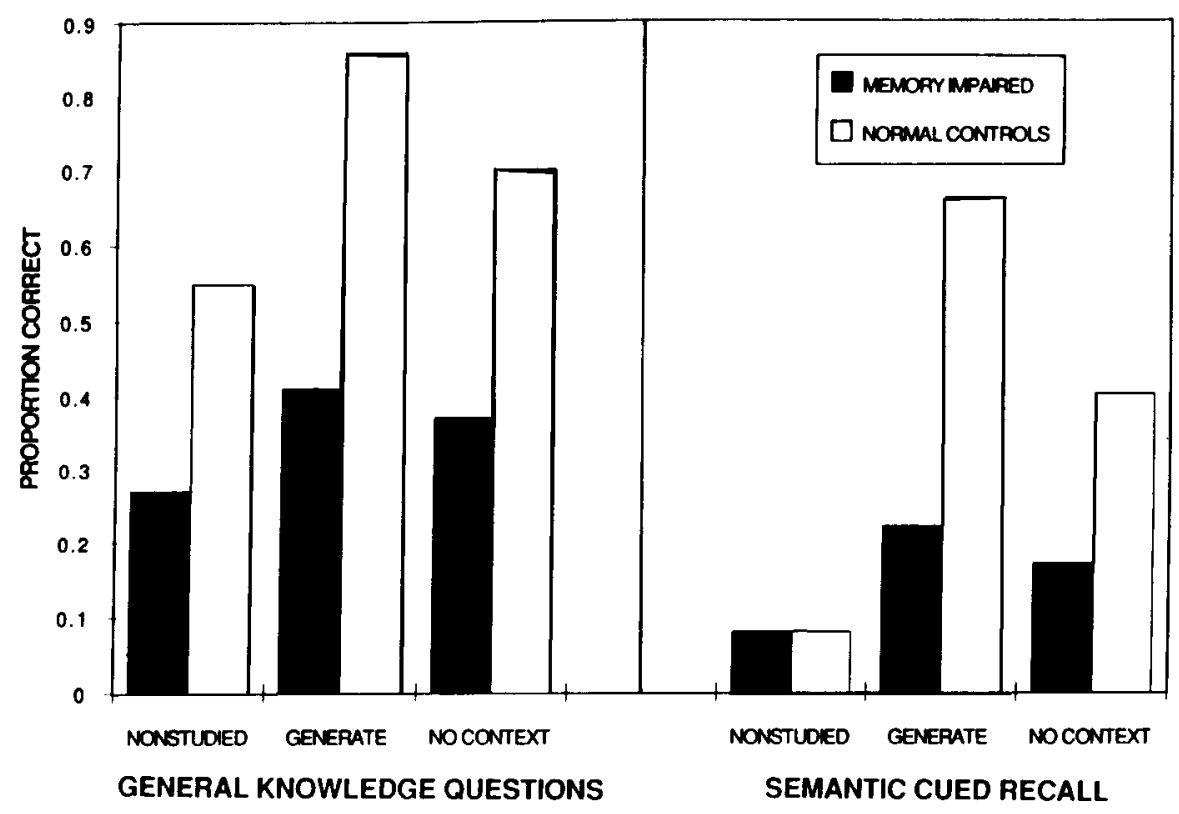

Figure 1. Proportion correct for conceptually driven tasks as a function of study condition and subject group in Experiment 1.

ter memory performance was observed in all studied conditions, relative to that observed in nonstudied conditions, for the conceptually driven tests. However, the same could not be said for the memory-impaired subjects. With an $L S D$ of .13, they failed to show significant advantage over nonstudied performance in the no-context condition of general knowledge (.37 for the no-context condition vs. .27 for the nonstudied condition). Likewise, the memoryimpaired patients showed statistically equivalent levels of performance in the no-context $(.17)$ and nonstudied $(.08)$ conditions of the semantic cued-recall test.

An ANOVA performed on data from the studied conditions for both groups revealed a main effect of task, reflecting higher performance levels overall for general knowledge than for semantic cued recall $[F(1,120)=$ 7.29. $\left.M S_{\mathrm{e}}=0.31\right]$. In addition, there were main effects of group $\left[F(1,120)=31.75, M S_{e}=1.37\right]$ and study condition $\left[F(1,120)=10.78, M S_{\mathrm{e}}=0.46\right]$. These effects indicate that the normal controls showed higher scores overall than did the patients and that transfer was greater in the generate condition than in the no-context condition.

Of greater interest was the finding of a significant study $x$ group interaction $\left[F(1,120)=6.91, M S_{e}=0.30\right]$. With an overall $L S D$ of .12, a generation effect was obtained on the conceptually driven tests for the normal controls, but not for the TLE subjects (see Figure 1). On the general knowledge task, the normal controls showed a significant advantage in the generate condition (.86) over the no-context condition (.70). A similar result was obtained for semantic cued recall, in which controls recalled more items that were studied in the generate condition (.66) than were read in the no-context condition (.40). However, the differences between these two study conditions did not approach significance on either test for the patient group. These findings reveal, then, that the memory-impaired TLE subjects have a deficit in conceptual transfer both on the explicit test of semantic cued recall and on the implicit test of answering general knowledge questions.

Data-driven memory tasks. Findings from the wordfragment completion and graphemic cued-recall tests are presented in Figure 2. An ANOVA including data from both studied and nonstudied conditions revealed a main effect of study $\left[F(2,180)=86.94, M S_{\mathrm{e}}=2.89\right]$. Performance was higher in the two studied conditions than in nonstudied conditions for both subject groups on fragment completion and graphemic cued recall.

The ANOVA including data from only the studied conditions revealed a main effect of task $[F(1,120)=10.64$, $\left.M S_{e}=0.46\right]$. Performance levels were higher overall for fragment completion than for graphemic cued recall. The main effect of study condition was also reliable $[F(1,120)$ $\left.=19.83, M S_{\mathrm{e}}=0.86\right]$, revealing significantly higher performance in the no-context condition than in the generate condition. There was also a main effect of group $[F(1,120)$ $=8.14, M S_{\mathrm{e}}=0.35$ ], reflecting generally lower performance levels for the patients than for their controls. As might be expected from Figure 2, there was no significant study $\times$ test interaction, since the finding of greater transfer from the no-context condition, relative to that from the generate condition, was obtained for both groups of subjects on both tasks. Inspection of transfer patterns on word-fragment completion showed that normal controls produced more items studied in the no-context condition (.86) than in the generate condition $(.71 ; L S D=$ .12). Memory-impaired subjects showed a similar advantage of no-context study (.85) over generate study (.66). 


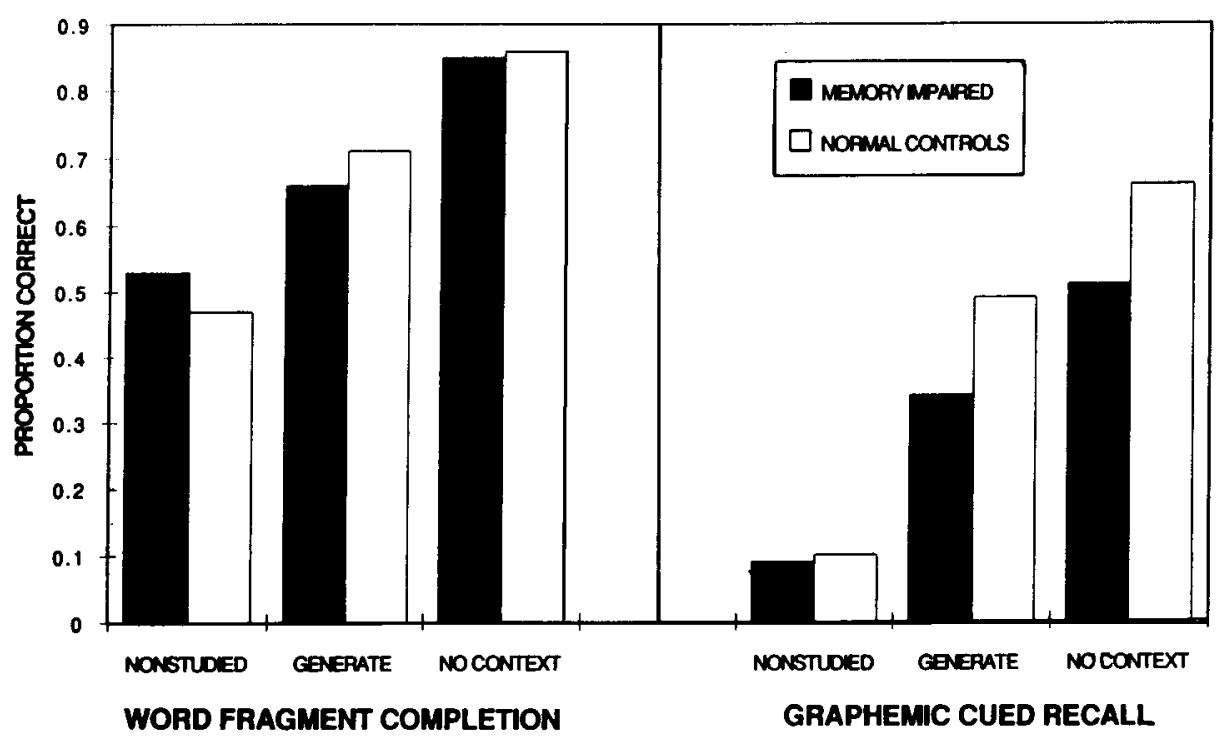

Figure 2. Proportion correct for data-driven tasks as a function of study condition and subject group in Experiment 1.

The same pattern of performance was observed for graphemic cued recall for normal controls (.66 vs .49 , nocontext advantage) and memory-impaired patients (.51 vs. .34 , no-context advantage.) In fact, the size of the difference between the no-context and generate conditions was statistically equivalent in all cases for the data-driven tests, suggesting that the ability to benefit from data-driven transfer is comparable in the TLE patients and their normal controls.

The most important finding of Experiment 1 was that the TLE patients showed deficits in transfer on both the general knowledge and the semantic cued-recall tests, although these same memory-impaired subjects showed normal patterns of performance on word-fragment completion and graphemic cued recall. This pattern of dissociations is easily characterized within a processing account of memory, in that the memory impairments of the TLE patients are confined to conceptually driven tests and are not observed on data-driven tasks. Given this pattern of results, it is of interest to ask whether a link may be made between deficits in conceptual transfer and site of neurological damage in the TLE patients. Experiment 2 was designed to explore this possibility.

\section{EXPERIMENT 2}

In Experiment 1, patients were included in the memoryimpaired subject group if they were impaired on the logical memory subtests of the revised version of the Wechsler Memory Scale (WMS-R). No criteria were adopted with regard to site of lesion in the first experiment. However, it is well known that lesions in the left temporal lobe often produce deficits in verbal memory function (e.g., Milner, 1967, 1971). It is not surprising, then, that most subjects in Experiment 1 had left temporal (13/16), as op- posed to right temporal $(1 / 16)$, seizure foci or lobectomy lesions. (Two subjects had bilateral foci.)

Once the impaired subject group is characterized in this fashion, the question of importance becomes one of whether deficits in conceptual transfer will be observed only for patients having left temporal foci or whether right temporal patients might show deficits as well. Most prior studies with TLEs have shown that patients with right temporal foci perform normally on verbal memory tasks, although the range of memory tasks generally given to these patients does not extend to the tests used in Experiment 1 (with the exception of semantic cued recall).

A separate issue arising from Experiment 1 is the question of whether the lack of conceptually driven transfer for the TLE patients was due more to their memory capabilities or to their overall cognitive function, as compared to the normal controls. That is, if the patient group had generic intellectual impairments relative to the normal controls, one might expect them to fare worse on such tests as semantic cued recall and general knowledge questions. Indeed, it was the case that the patient group had lower baseline rates on the general knowledge task than did the normals, lending some credence to this possibility.

The problem in addressing this issue is in choosing a proper means of equating groups on overall cognitive function. Rather than equating patient and normal control groups on the basis of IQ scores, ${ }^{1}$ the approach taken in this experiment was to compare the memory-impaired left TLE subjects with right TLE patients who were taking similar medications and whose scores on standard neuropsychological memory measures fell within normal ranges. If the lack of conceptual transfer observed in Experiment 1 was due simply to general cognitive deficits in the memory-impaired group, one would expect to see similar patterns of transfer in Experiment 2 for the left 
Table 1

Characteristics of Subject Groups Tested in Experiment 2

\begin{tabular}{|c|c|c|c|c|c|c|c|c|c|c|c|c|c|c|c|c|c|}
\hline \multirow{2}{*}{\multicolumn{2}{|c|}{$\begin{array}{c}\text { Age } \\
\text { (years) }\end{array}$}} & \multirow{2}{*}{\multicolumn{2}{|c|}{$\begin{array}{c}\text { Education } \\
\text { (years) }\end{array}$}} & \multirow{2}{*}{\multicolumn{2}{|c|}{ Surgery }} & \multicolumn{6}{|c|}{ WAIS-R } & \multicolumn{6}{|c|}{ WMS-R } \\
\hline & & & & & & \multicolumn{2}{|c|}{ WAIS-R } & \multicolumn{2}{|c|}{ Verbal } & \multicolumn{2}{|c|}{ Performance } & \multicolumn{2}{|c|}{ WMS-R } & \multicolumn{2}{|c|}{ LM I* } & \multicolumn{2}{|c|}{ LM II* } \\
\hline$M$ & Range & $M$ & Range & Pre & Post & $M$ & Range & $M$ & Range & $M$ & Range & $M$ & Range & $\boldsymbol{M}$ & Range & $M$ & Range \\
\hline \multicolumn{18}{|c|}{ Left-Temporal-Lobe Epileptics } \\
\hline 33.4 & $28-52$ & 14.0 & $12-18$ & 9 & 7 & 94.2 & $82-115$ & 91.6 & $81-121$ & 97.7 & $80-139$ & 105.5 & $81-123$ & 20.0 & $1-47$ & 13.1 & $1-36$ \\
\hline \multicolumn{18}{|c|}{ Right-Temporal-Lobe Epileptics } \\
\hline 34.1 & $24-49$ & 14.0 & $12-18$ & 8 & 8 & 102.9 & $82-129$ & 98.9 & $81-128$ & 98.6 & $82-122$ & 124.7 & $107-167$ & 82.6 & $70-99$ & 80.1 & $58-97$ \\
\hline
\end{tabular}

Note-Percentile scores are reported for the Logical Memory subtests (*Logical Memory I and Logical Memory II). Each group of subjects consisted of 8 males and 8 females.

TLE and right TLE patients. However, if the lack of conceptual transfer is specifically related to memory deficits, the right TLE group should perform similarly to normal controls, even though they may show lower baseline performance rates than those of the normals.

These issues were explored in Experiment 2 using the same methodology employed in Experiment 1. Two groups of TLE subjects were tested, one group having left temporal foci and the other having right temporal foci. The design was a 2 (subject group: left TLEs, right TLEs) $\times 3$ (study condition: no context, generate, nonstudied) $\times 4$ (memory task: semantic cued recall, graphemic cued recall, word-fragment completion, general knowledge questions) mixed factor design.

\section{Method}

Subjects. Two groups of 16 subjects each were tested in Experiment 2 . All subjects were patients who had been diagnosed with intractable TLE and had either been admitted to NIH as surgical candidates for the temporal lobectomy procedure or had already received the surgery. All subjects had lateralized seizure foci in the mesial and lateral temporal lobes as confirmed by surface and/or subdural EEG data. Additional confirmatory evidence was avail- able for some subjects from MRI and PET scans. Seizure foci and lobectomy lesions were confined to the left temporal lobe in one group of patients, whereas foci and lesions were lateralized in the right temporal lobe in the other group. Relevant characteristics of the subject groups as well as their scores on the WAIS-R and WMS-R are presented in Table 1 . The most important point to note is that although both patient groups had WAIS-R scores within normal ranges, the left TLE group was impaired on the WMS-R Logical Memory I and II subtests, relative to the right TLE group. All other aspects of the experimental design and procedure were identical to those employed in Experiment 1.

\section{Results and Discussion}

As in Experiment 1, ANOVAs including test order as a factor revealed that this variable produced no significant main effects or interactions. Collapsing across test order, analyses similar to those described in Experiment 1 were performed. All confidence levels were set at $p<.05$.

Conceptually driven tests. Proportion correct as a function of study condition, memory task, and subject group is presented in Figure 3. An ANOVA including proportion correct scores for studied and nonstudied items revealed a main effect of study condition $[F(2,180)=$

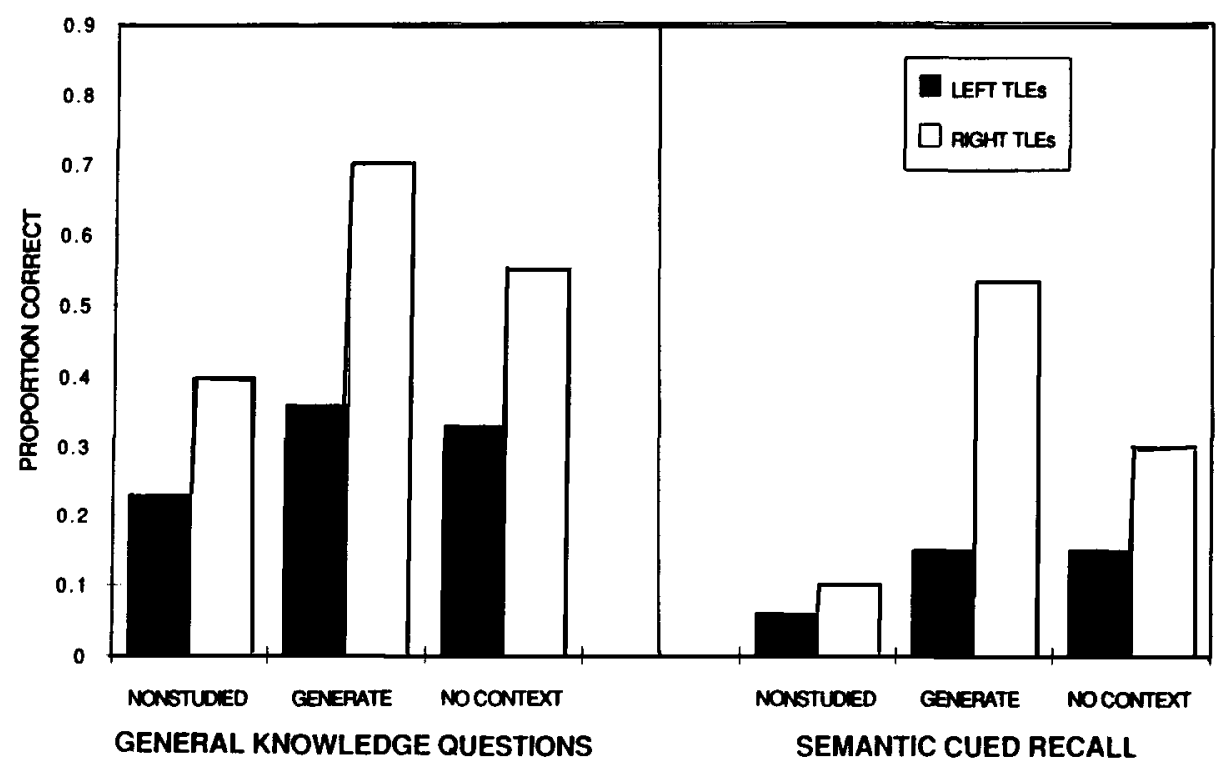

Figure 3. Proportion correct for conceptually driven tasks as a function of study condition and subject group in Experiment 2. 
$\left.23.54, M S_{\mathrm{e}}=1.05\right]$. With an $L S D$ of .09 , higher performance levels were obtained in studied conditions than in nonstudied conditions for both tasks for both subject groups.

To assess differential transfer as a function of study condition, an ANOVA including data only from studied conditions was performed. This analysis revealed a main effect of study condition $\left[F(1,120)=6.92, M S_{e}=.38\right]$, with more targets produced overall in the generate condition than in the no-context condition. A main effect of subject group was also reliable $\left[F(1,120)=48.33, M S_{e}\right.$ $=2.67 \mathrm{]}$, reflecting the fact that performance was lower for the left TLE group than for the right TLE patients. Finally, there was a main effect of memory task $[F(1,120)$ $=19.16, M S_{\mathrm{e}}=1.06$ ], due to higher proportion correct scores in the general knowledge test than in the semantic cued-recall test.

Of greater interest was the interaction between study condition and subject group $\left[F(1,120)=4.40, M S_{e}=\right.$ .24 , reflecting the fact that generation effects were obtained for both tasks for the right TLEs, but not for the left TLE group. With an overall $L S D$ of .10, the improvement in performance in the generate condition, relative to the no-context condition, did not approach significance for the left TLE group for either semantic cued recall (.15 vs. .15) or general knowledge questions (.36 vs. .33). Right TLEs, in contrast, showed generation effects for both semantic cued recall (.53 vs. .30) and general knowledge (.70 vs. .55). No other interactions were statistically reliable.

The results for individual subjects within the patient groups were quite consistent. For semantic cued recall, 13/16 left TLEs failed to show generation effects, with the exceptions being 2 presurgery and 1 postsurgery patient. Conversely, 14/16 right TLEs showed generation effects, with only 1 presurgery and 1 postsurgery patient failing to do so. As a point of comparison, 14/16 normal controls showed generation effects on semantic cued recall in Experiment 1.

A similar pattern emerged for the general knowledge task, with 13/16 left TLEs failing to show more transfer from the generate study condition than from the no-context study condition. Of the 3 exceptions, 1 had previously had a temporal lobectomy and 2 were surgical candidates. Thirteen out of 16 right TLEs did show generation effects on the general knowledge test, and only 2 presurgery and 1 postsurgery patient failed to show this transfer pattern. This is comparable to the results found with normal controls in Experiment 1, in which 13/16 subjects (6 postsurgery and 7 presurgery) showed better performance in the generate condition than in the no-context condition.

Data-driven tests. Proportion correct as a function of study condition, memory test, and subject group is presented in Figure 4. An ANOVA including data from nonstudied items revealed a main effect of study condition $\left[F(2,180)=84.35, M S_{c}=2.48\right]$, reflecting higher performance overall in the studied conditions, relative to that in the nonstudied conditions ( $L S D=.07$ ). An ANOVA including proportion correct data from only studied items showed a main effect of study condition $[F(1,120)=22.89$, $\left.M S_{e}=.70\right]$, reflecting better performance overall in the no-context study conditions than in the generate study conditions for both tests. A main effect of subject group was also reliable $\left[F(1,120)=5.15, M S_{\mathrm{e}}=.16\right]$, indicating that performance was lower in the left TLE group than in the right TLE group. Finally, a main effect of memory test

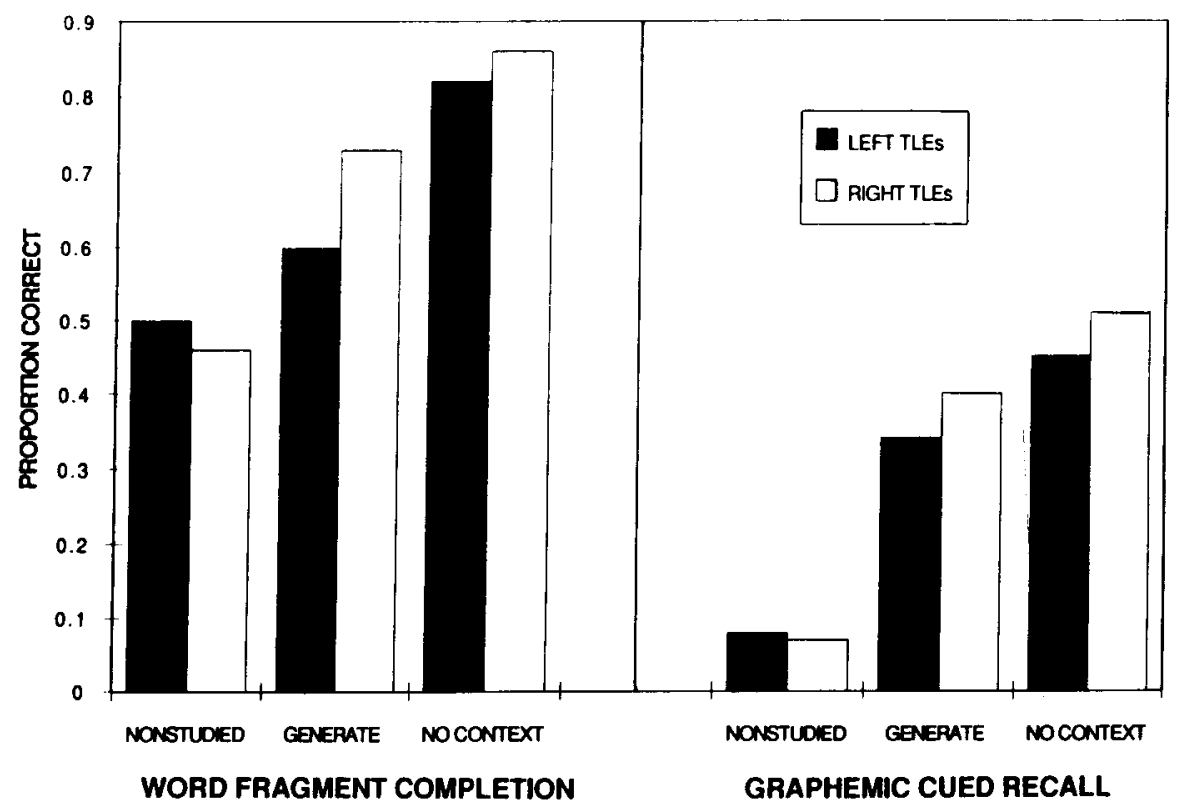

Figure 4. Proportion correct for data-driven tasks as a function of study condition and subject group in Experiment 2. 
reflected higher scores for fragment completion than for graphemic cued-recall $\left[F(1,120)=109.52, M S_{e}=3.37\right]$. No reliable interactions were observed.

With an overall $L S D$ of .07 , the greater transfer from the no-context condition, relative to that from the generate condition, for fragment completion was reliable for the left TLEs (.82 vs. .60$)$ and for the right TLEs (.86 vs. .73; see Figure 4). A similar advantage was observed for the no-context condition, relative to the generate condition, in graphemic cued recall for the left TLEs (.45 vs. .34) and right TLEs (.51 vs. .40). This suggests that both the left and right temporal groups showed normal data-driven transfer on these memory tasks. Thus, the left TL.E group's verbal memory deficits, as measured by the Logical Memory subtests of the WMS-R, occur despite the fact that their memory on data-driven verbal tasks is normal.

The transfer effects just described were observed rather uniformly across patient groups regardless of whether the subjects had previously had surgery. For fragment completion, all 16 left TLEs showed the effect. Only 2 right TLEs failed to show the effect, both of whom had previously had surgery. These numbers compare favorably to those observed for normal controls in Experiment 1, in which all 16 subjects produced more studied items in the no-context condition than in the generate condition. On the graphemic cued-recall task, 14 of 16 left TLEs showed more transfer from the no-context condition than from the generate condition, with the 2 exceptions being presurgery patients. Fifteen out of 16 right TLEs showed the effect, with only 1 presurgery patient failing to do so. Similarly $15 / 16$ of the normal controls tested in Experiment I showed this pattem of results.

The findings from these memory tasks are interesting from a neuropsychological viewpoint, in that they show consistent transfer patterns as a function of lesion site irrespective of pre/postsurgical status. This is important because there has been a certain amount of controversy with regard to how well one can identify hernisphere of epileptic focus by observing memory performance in presurgery patients (Andrewes, Puce, \& Bladin, 1990; Delaney, Rosen, Mattson, \& Novelly, 1980; Mungas, Ehlers, WalIon, \& McCutchen, 1985). In this small group of subjects, at least, the tests employed in Experiments 1 and 2 appear to fare quite well in this regard.

\section{EXPERIMENT 3}

The results from Experiments 1 and 2 demonstrate that performance on semantic cued recall and general knowledge question tasks is impaired in TLE subjects having left temporal lobe damage. From the neuropsychological literature on these patients, we know also that their performance is impaired on other memory tests, such as free rocall and recognition. These impaiments are dissociated, however, from the intact performance observed for other mernory tasks, such as fragment completion and graphe- mic cued recall. This pattern of results may be interpreted within the framework of the processing account of memory in that these patients are impaired on memory paradigms requiring conceptually driven, but not data-driven, transfer. Evidence for such a conclusion would be stronger, however, if it could be demonstrated that an analogous deficit is obtained with the left TLE subjects using a different conceptuaily driven memory task and different study materials.

As already noted, the finding of conceptual transfer deficits on the implicit test of general knowledge questions in Experiments 1 and 2 runs counter to findings observed in analogous paradigms in which other memoryimpaired patient groups have been tested. One such paradigm is that of category member production, which has been described elsewhere as an implicit conceptually driven task (e.g., Hamann, 1990; Rappold \& Hashtroudi, 1991; Srinivas \& Roediger, 1990). Previous studies testing memory-imparred subjects have sometimes shown that they perform normally on category production (e.g., J. Gabrieli, personal communication, 1991; Gardner et al., 1973; Graf et al., 1985, Experiment 2). Given results such as these, it is important to establish whether the particular memory-impaired subject group tested in the present set of experiments would show similar patterns of results on category production.

This question was addressed in Experiment 3, in which memory-impaired TLEs were given a category production task along with an explicit semantic cued-recall test. An encoding manipulation was employed, whereby items were presented for study in a random order or blocked by category. As has been shown by Rappold and Hashtroudi (1991), normal subjects produce more previously studied items on category production tasks if those items are blocked by category during study than they do if the items are presented randomly. Many similar demonstrations have been reported previously with conceptually driven explicit tests, such as free and cued recall (see Tulving \& Donaldson, 1972). The processing account predicts these results because the additional conceptual organization embodied in the blocked condition should evoke conceptually driven analysis during study that transfers well to performance of the conceptually driven memory test. Thus, it is predicted that performance should be higher in the blocked condition than in the random condition for both memory tests for normal control subjects as well as nonimpaired right TLE patients. However, in keeping with findings from the general knowledge task in Experiments 1 and 2 , the processsing account predicts that the memory impairments of the left TLE subjects will be reflected in a lack of differential transfer as a function of study condition on these tasks.

\footnotetext{
Method

Subjects. Characteristics of the subjects tested in Experiment 3 are presented in Table 2 . Three groups of 16 subjects each were tested in the experiment. The first of these was a group of memoryimpaired left TlEs similar to those tested in Experiments : and
} 
Table 2

Characteristics of Subject Groups Tested in Experiment 3

\begin{tabular}{|c|c|c|c|c|c|c|c|c|c|c|c|c|c|c|c|c|c|}
\hline \multirow{2}{*}{\multicolumn{2}{|c|}{$\begin{array}{c}\text { Age } \\
\text { (years) }\end{array}$}} & \multirow{2}{*}{\multicolumn{2}{|c|}{$\begin{array}{c}\text { Education } \\
\text { (years) }\end{array}$}} & \multirow{2}{*}{\multicolumn{2}{|c|}{ Surgery }} & \multicolumn{6}{|c|}{ WAIS-R } & \multicolumn{6}{|c|}{ WMS-R } \\
\hline & & & & & & \multicolumn{2}{|c|}{ WAIS-R } & \multicolumn{2}{|c|}{ Verbal } & \multicolumn{2}{|c|}{$\overline{\text { Performance }}$} & \multicolumn{2}{|c|}{ WMS-R } & \multicolumn{2}{|c|}{ LM I* } & \multicolumn{2}{|c|}{ LM II* } \\
\hline$M$ & Range & $M$ & Range & Pre & Post & $M$ & Range & $M$ & Range & $M$ & Range & $M$ & Range & $M$ & Range & $M$ & Range \\
\hline \multicolumn{18}{|c|}{ Left-Temporal-Lobe Epileptics } \\
\hline 33.4 & $28-52$ & 14.0 & $12-18$ & 8 & 8 & 94.2 & $86-115$ & 91.6 & $81-121$ & 97.7 & $80-139$ & 99.2 & $81-119$ & 24.0 & $2-49$ & 19.0 & $3-36$ \\
\hline \multicolumn{18}{|c|}{ Right-Temporal-Lobe Epileptics } \\
\hline 34.1 & $23-49$ & 14.1 & $12-18$ & 8 & 8 & 99.6 & $86-117$ & 98.9 & $81-128$ & 98.6 & $82-122$ & 120.0 & $107-153$ & 74.0 & $56-99$ & 72.0 & $56-97$ \\
\hline \multicolumn{18}{|c|}{ Normal Controls } \\
\hline 32.6 & $22-48$ & 13.3 & $12-16$ & & & & & & & & & & & & & & \\
\hline
\end{tabular}

Note-Percentile scores are reported for the Logical Memory subtests (*Logical Memory I and Logical Memory II). Each group of subjects consisted of 8 males and 8 females.

2. A second group of right TLEs having normal memory function and a group of normal controls were tested. As shown in Table 2, the left TLEs were severely impaired in immediate and delayed recall of narrative passages as evidenced by their percentile scores on the logical memory subtests of the WMS-R. This occurred despite the fact that their WAIS-R scores fell within normal ranges.

Materials and Design. Twelve categories were selected from the Battig and Montague (1969) category norms for use in the experiment. Five items of medium to low dominance were identified to serve as target items from each category. The categories were divided into two six-category base lists. Half of the subjects studied one base list, and half studied the other base list. Each base list was divided into two 15 -item sublists, one to be presented prior to the first memory test and the other to be studied before the second memory test. Two versions of each 15 -item sublist were constructed. In one of these, words were presented blocked by semantic category; in the other, the same items were presented in a random order. Half of the subjects in the experiment studied the randomized lists, and half studied the blocked lists. Three filler items were added to the top and the bottom of every sublist, such that the subjects studied lists of 21 words prior to taking a memory test.

Two types of memory tasks were employed. The first of these was a category production test in which the subjects generated eight exemplars each to six category labels. The second was a semantic cued-recall test in which category labels were presented as retrieval cues for items presented during study. The only difference between these two memory tests was the implicit or explicit instruction given to the subjects at time of test presentation. Tests were constructed such that half of the category labels corresponded to studied items and half corresponded to nonstudied items. Materials were counterbalanced such that the studied categories for half of the subjects were the nonstudied categories for the other subjects and vice versa. The two sublists of a base list were always presented for study in the same order. Half of the subjects received the category member generation task after studying the first sublist, and half received the semantic cued-recall test after the first sublist.

These experimental manipulations resulted in a 3 (subject group: left TLEs, right TLEs, and normal controls) $\times 3$ (study condition: blocked, random, nonstudied) $\times 2$ (type of test: category production, semantic cued recall) mixed design. Subject group and study condition (blocked vs. random) were between-subject variables, and type of test was manipulated within subjects.

Procedure. The subjects were tested individually and were told that they would be performing a series of language and memory tasks. During the study phases, the experimenter read the study lists aloud to the subjects at a rate of one item per $5 \mathrm{sec}$. As words were presented, the subjects were asked to provide liking ratings of item referents by circling numbers on a 5 -point scale, in which a rating of 1 corresponded to like extremely and 5 corresponded to dislike extremely. The subjects received the first memory task immediately following presentation of the first study sublist. The subjects performing the category production test were instructed to write down the first eight exemplars that they could think of for each category label. The subjects receiving the semantic cued-recall test were given the category production test form but were told to write down only studied items beneath the appropriate category labels. No time limits were imposed for either task, and the subjects were allowed to complete items within a test in any order they chose. Following completion of the first test, the study procedure was repeated with a different study list and the other test given. The entire procedure lasted approximately $25 \mathrm{~min}$.

\section{Results and Discussion}

Results in terms of proportion correct as a function of study condition and subject group are presented in Figure 5. An ANOVA performed on the combined data from all subject groups revealed a main effect of study condition $\left[F(1,168)=373.57, M S_{\mathrm{e}}=4.63\right]$. (All confidence levels were set at $p<.05$ ). This reflected the fact that performance in all studied conditions was reliably higher than performance in nonstudied conditions in both memory tests for all subject groups $(L S D=.04)$.

A second ANOVA performed only on proportion correct scores from studied conditions revealed a main effect of type of memory test $\left[F(1,84)=16.88, M S_{e}=\right.$ $0.37]$, which was produced by generally higher levels of test performance on semantic cued recall, relative to those on category production. Two other main effects were observed for the factors of subject group $[F(2,84)=7.02$, $\left.M S_{\mathrm{e}}=0.09\right]$ and study condition $\left[F(1,84)=12.54, M S_{\mathrm{e}}\right.$ $=0.27]$. Of greater interest than these main effects was the reliable group $\times$ study interaction $[F(2,84)=8.07$, $\left.M S_{\mathrm{e}}=0.18\right]$. With an overall $L S D$ of .07 , higher performance levels were observed in the blocked conditions than in the random conditions for category production for both right TLEs (.43 vs. .27) and normal subjects (.41 vs. .31; see Figure 5). The memory-impaired left TLEs, however, showed statistically equivalent levels of performance in the two study conditions. Similarly, this blocked-overrandom advantage was observed in semantic cued recall for right TLEs (.52 vs. .32) and normals (.64 vs. .47), 


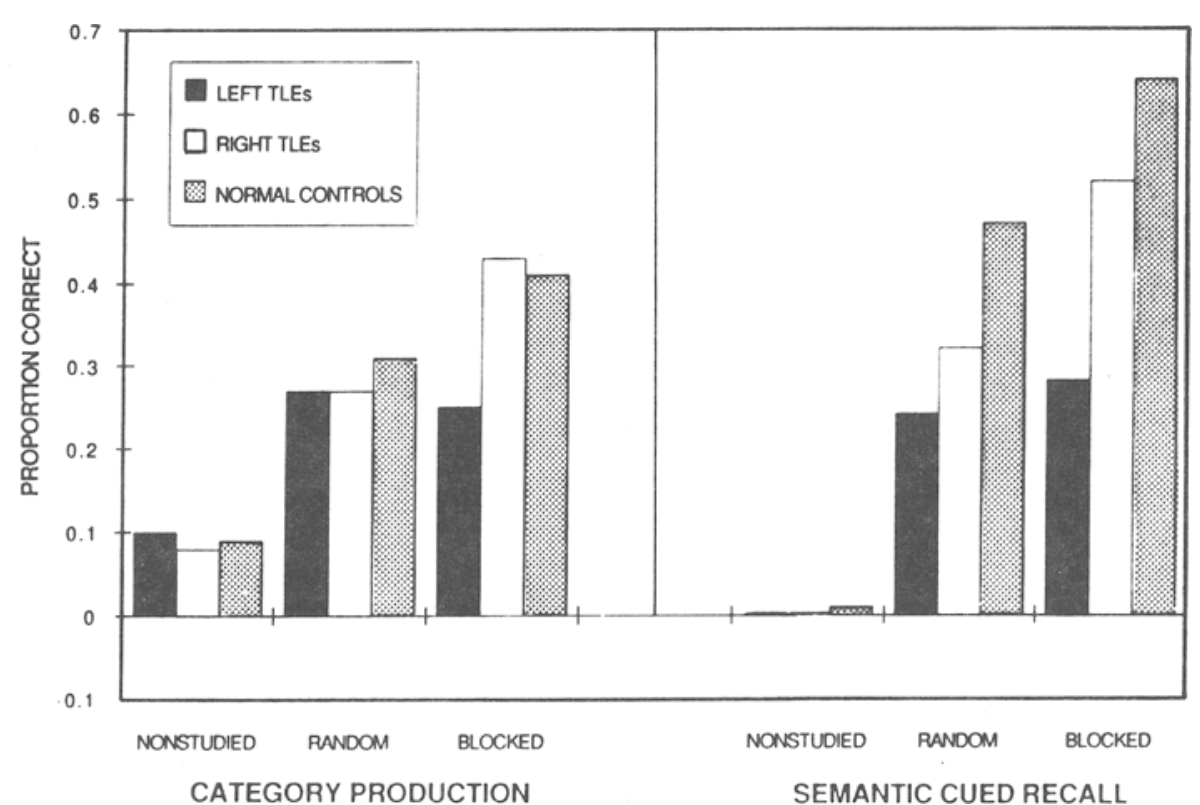

Figure 5. Proportion correct for category production and semantic cued recall as a function of study condition and subject group in Experiment 3.

although the left TLEs again failed to show any differential effect of study condition. Thus, the left TLEs, unlike the two control groups, failed to benefit from the extra conceptual transfer from the blocked study condition on either memory test.

Given the parallel effects of semantic organization on the two memory tests, it is important to determine whether the subjects were actually engaging in different retrieval modes when performing these tests as they were instructed (see Neely \& Payne, 1983; Schacter, Bowers, \& Booker, 1989). Evidence supporting the claim that different retrieval processes were indeed engaged comes from two sources. First, the factor of subject group affected level of performance on semantic cued recall but not performance on category production. In semantic cued recall, the normal subjects recalled more studied items than did the right TLEs in both the random condition (.47 vs. .32) and blocked condition (.64 vs. $.52 ; L S D=.07)$. Right TLEs in turn performed better than the memory-impaired left TLEs, whose recall levels in the random and blocked conditions were .24 and .28 . Despite these group differences in semantic cued recall, all subject groups showed equal levels of performance in the random study condition in category production; the right TLE and normal control groups produced equal numbers of targets in the blocked condition.

Further evidence of a dissociation between category production and cued recall was provided by an analysis of response protocols on the two memory tasks examining targets produced in the first three output positions on the memory tests. If, in fact, the subjects followed the explicit retrieval instructions on the semantic cued-recall test, one would expect them to write only target items in the first three output positions for each category on the test. By the same token, if the subjects performed the category production task in an implicit retrieval mode, one would expect nonstudied items to be mixed in randomly with targets in these first three positions (see Rappold \& Hashtroudi, 1991, for a similar analysis). An ANOVA was performed on the proportions of target items produced in the first three output positions for studied categories for both subject groups on the two memory tests. This analysis revealed main effects of subject group $[F(2,90)=7.17$, $\left.M S_{\mathrm{e}}=.40\right]$ and memory task $\left[F(1,90)=62.31, M S_{\mathrm{e}}=\right.$ 3.49 ]. With an overall $L S D$ of .15, it was found that more targets were produced in the first three output positions for semantic cued recall than for category production for normal controls (.79 vs. .31 ), right TLEs (.67 vs. .25 ), and memory-impaired left TLEs (.45 vs. .20).

These findings indicate that the subjects were indeed following the implicit and explicit instructions given on the memory tasks. Thus, the lack of conceptual transfer obtained in this experiment for the left TLEs occurred under both implicit and explicit retrieval conditions. The findings of Experiments 1 and 2 are supported and extended in that the memory-impaired left TLEs showed deficits in conceptual transfer on a conceptually driven implicit task other than answering general knowledge questions-namely, category production. Since this result occurred in conjunction with a comparable lack of conceptual transfer on the explicit cued-recall task, these data are easily accommodated by the processing account.

Results from Experiment 3 speak to two other issues raised by findings obtained in Experiments 1 and 2. First, the abnormal patterns of conceptual transfer on the category production and general knowledge question tasks ap- 
pear at first glance to be at odds with those reported elsewhere in which amnesic subjects have normal patterns of performance on category production tests (e.g., J. Gabrieli, personal communication, 1991; Gardner et al., 1973; Graf et al., 1985, Experiment 2; but see Shimamura \& Squire, 1989). However, the designs in those studies did not permit examination of differential transfer in memory paradigms as a function of study condition since no study manipulations were employed (other than the comparison between studied and nonstudied items.) The analogous comparison between this and previous experiments with amnesic patients, then, is the random study condition. Since the memory-impaired TLE subjects did show transfer levels equivalent to that of controls in the random condition, the present results are not at odds with previous demonstrations. The more relevant finding with regard to the processing account of memory, however, is the absence of a benefit in the blocked condition relative to the random condition for impaired subjects. Indeed, the theory does not predict that there will be no transfer whatsoever on conceptual tasks-it predicts that the differential benefit from conceptual, as opposed to data-driven, encoding observed in normals will be compromised.

These data also address a second concern that the patient results of Experiments 1 and 2 reflected generic cognitive deficits, as opposed to memory impairments, on verbal tasks. In Experiment 3, the lack of extra conceptual transfer for the impaired TLEs occurred despite the fact that their performance levels were equivalent to those observed for the epileptic control group in the nonstudied and random conditions of the category production test. Thus, the failure of the impaired left TLE group to benefit from the extra conceptual organization in the blocked study conditions was not due to a generic deficit on verbal tasks, for if this were the case one would have expected them to have lower performance levels than the right TLEs in the nonstudied and random conditions on the category production test. ${ }^{2}$ Rather, it is argued that the pattern of results reflects a deficit in conceptual transfer for the left TLE impaired group that is independent of verbal abilities.

\section{GENERAL DISCUSSION}

Experiments 1-3 examined dissociations among several memory tasks in both normal subjects and TLEs. Results from Experiment 1 indicated that memory-impaired TLEs showed intact data-driven transfer on tests of graphemic cued recall and word-fragment completion, with higher performance for items presented in data-driven (nocontext) study conditions than in conceptually driven (generate) study conditions. On the conceptually driven tests of answering general knowledge questions and semantic cued recall, however, only the normal control subjects showed a reversal of this effect, with more transfer in the generate study conditions than in the no-context conditions. This result was further explored in Experiment 2, in which performance on these tasks was assessed for TLE patients having either left or right temporal seizure foci. In Experiment 2, it was shown that while both groups of TLEs showed normal patterns of data-driven transfer, the left TLE group failed to show conceptual transfer on the semantic cued-recall and general knowledge tasks. An extension of this finding was provided in Experiment 3, in which normal controls and right TLEs showed greater conceptual transfer in blocked study conditions than in random study conditions on conceptual tasks of category production and semantic cued recall, although memoryimpaired left TLEs failed to show any differential transfer in these tasks. Thus, the left temporal subjects appeared to show intact data-driven transfer but deficits in conceptual transfer.

As stated at the outset, these experiments were designed to explore the degree to which findings from dissociation paradigms in which memory-impaired subjects are tested may be accommodated by the processing account of memory. Data from the present studies suggest that memoryimpaired left TLE subjects show deficits on memory tasks for which conceptual transfer is critical, although their performance on data-driven verbal memory tasks appears quite normal. Support for this claim was obtained, in that the memory-impaired TLEs showed deficits in conceptual transfer on tasks of general knowledge questions, semantic cued recall, and category production.

One intriguing aspect of these data is that the deficits in conceptual transfer for the left TLEs occurred on implicit as well as explicit tests. This finding runs counter to predictions made by some memory systems theories that postulate that memory-impaired subjects have deficits in explicit but not implicit memory. A pertinent exámple is Tulving and Schacter's (1990) theory in which memory is said to be subserved by distinct episodic (explicit), semantic (implicit), and perceptual representation systems. Tulving and Schacter have argued that the poor memory performance observed in neurologically damaged patients reflects an impairment that specifically affects episodic memory function but that spares the semantic and perceptual representation systems. Findings from the particular patients tested in the present experiments, however, would suggest that the left TLE patients do not have intact semantic memory function as measured by the implicit semantic tests of answering general knowledge questions and category production. Furthermore, the left TLEs did not show global impairment on episodic tasks as predicted by the systems theory, in that they performed normally on the data-driven explicit task of graphemic cued recall. Thus, the left TLE subjects are one example of a memory-impaired subject group whose deficits (1) suggest semantic memory impairments and (2) do not extend across the entire realm of episodic memory function.

In closing, the pattern of dissociations among memory measures observed in this series of experiments may be accommodated by a processing account of memory in which memory-impaired left TLE subjects show intact performance on data-driven memory tasks but deficits in conceptual transfer paradigms. What remains to be seen, 
however, is the extent to which this pattern of results may be replicated across various other memory-impaired patient groups having different underlying pathologies (see Weiskrantz, 1985). Clearly, the greatest strides in this area will result from comparisons across strictly defined lesion groups, using a wide variety of study manipulations and tests. These experimental outcomes should provide some of the most critical information to be used in the modification and development of theoretical accounts of dissociations among memory measures.

\section{REFERENCES}

Andrewes, D. G., Puce, A., \& Bladin, P. F. (1990). Post-ictal rec ognition memory predicts laterality of temporal lobe seizure focus: Comparison with post-operative data. Neuropsychologia, 28, 957-967.

Battig, W. F., Montague, W. E. (1969). Category norms for ver bal items in 56 categories: A replication and extension of the Connecticut category norms. Journal of Experimental Psychology Monograph, 80(3, Pt. 2), 1-45.

Blaxton, T. (1989). Investigating dissociations among memory measures: Support for a transfer appropriate processing framework. Journal of Experimental Psychology: Learning, Memory, \& Cognition, $15,657-668$.

BlaXTON, T. (1992). The role of the temporal lobes in memory for nonverbal materials: Conceptual and data-driven transfer. Manuscript submitted for publication.

Bornstein, R. A., Chelune, G. J. (1988). Factor structure of the Wechsler Memory Scale Revised. Clinical Neuropsychologist, 2 , 107-115.

Cermak, L. S. (1989). Synergistic ecphory and the amnesic patient. In H. L. Roediger III \& F. I. M. Craik (Eds.), Varieties of memory and consciousness: Essays in honour of Endel Tulving (pp. 121-131). Hillsdale, NJ: Erlbaum.

Cermak, L. S., ButTers, N. (1972). The role of interference and encoding in the short-term memory deficits of Korsakoff patients. Neuroprychologia, 10, 89-96.

Cermak, L. S., Butters, N., aerrein, J. (1973). The extent of the verbal encoding ability of Korsakoff patients. Neuropsychologia, 11, 85-94.

Cermak, L. S., Butters, N., \& Moreines, J. (1974). Some analyses of the verbal encoding deficit of alcoholic Korsakoff patients. Brain \& Language, 1, 141-150.

Cermak, L. S., Naus, M. J., Reale, J. (1976). Rehearsal and organizational strategies of alcoholic Korsakoff patients. Brain \& Language, 3, 375-385.

Cermak, L. S., Talbot, N., Chandler, K., \&olbarst, L. R. (1985). The perceptual priming phenomenon in amnesia. Neuropsychologia, 23, 615-622.

Cohen, N. J. (1984). Preserved learning capacity in amnesia: Evidence for multiple memory systems. In L. S. Squire \& N. Butters (Eds.), Neuropsychology of memory (pp. 83-103). New York: Guilford.

Delaney, R. C., Rosen, A. J., Mattson, R. H. , Novelly, R. A. (1980). Memory function in focal epilepsy: A comparison of nonsurgical unilateral temporal lobe and frontal lobe samples. Cortex, 16, 103-117.

Gardner, H., Boller, F., Moreines, J., \& Butters, N. (1973). Retrieving information from Korsakoff patients: Effects of categorical cues and reference to the task. Cortex, 9, 165-175.

Graf, P., SChacter, D. (1985). Implicit and explicit memory for new associations in normal and amnesic subjects. Joumal of Experimental Psychology: Leaming, Memory, \& Cognition, 11, 501-518.

Graf, P., Shimamura, A. P., \& Suire, L. R. (1985). Priming across modalities and priming across category levels: Extending the domain of preserved function in amnesia. Joumal of Experimental Psychology: Learning, Memory, \& Cognition, 11, 386-396.

Graf, P., Squire, L. S., Mandler, G. (1984). The information that amnesic patients do not forget. Journal of Experimental Psychology: Learning, Memory, \& Cognition, 10, 164-178.
HamanN, S. (1990). Level-of-processing effects in conceptually driven implicit tasks. Journal of Experimental Psychology: Leaming, Memory, \& Cognition, 16, 970-977.

JACOBY, L. L. (1983). Remembering the data: Analyzing interactive processes in reading. Joumal of Verbal Leaming \& Vertbal Behavior, 22, 485-508.

Johnson, M. K., KIM, J. K., Risse, G. (1985). Do alcoholic Korsakoff's syndrome patients acquire affective reactions? Joumal of Experimental Psychology: Learning, Memory, \& Cognition, 11, 23-36.

Mayes, A. R., Meudell, P. R., Pickering, A. (1985). Is organic amnesia caused by a selective deficit in remembering contextual information? Cortex, 21, 167-202.

McAndrews, M. P., Gusky, E. L., Schacter, D. L. (1987). When priming persists: Long-lasting implicit memory for a single episode in amnesic patients. Neuropsychologia, 25, 497-506.

MILNER, B. (1967). Brain mechanisms suggested by studies of temporal lobes. In F. C. Darley (Ed.), Brain mechanisms underlying speech and language (pp. 122-132). New York \& London: Grune \& Stratton.

Milner, B. (1971). Interhemispheric differences in the localization of psychological processes in man. British Medical Bulletin, 27, 272-277.

Morris, C. D., Bransford, J. D., Franks, J. J. (1977). Levels of processing versus transfer appropriate processing. Journal of Verbal Learning \& Verbal Behavior, 16, 519-533.

Moscovitch, M. (1984). The sufficient conditions for demonstrating preserved memory in amnesia: A task analysis. In L. R. Squire \& N. Butters (Eds.), Neuropsychology of memory (pp. 104-114). New York: Guilford

Mungas, D., Ehlers, C., Walton, N., McCutchen, C. B. (1985). Verbal learning differences in epileptic patients with left and right temporal foci. Epilepsia, 246, 340-345.

NeEly, J. H., \& PAYNe, D. G. (1983). A direct comparison of recognition failure rates for recallable names in episodic and semantic memory tests. Memory \& Cognition, 11, 161-171.

Nissen, M. J., Cohen, N. J., \& Corkin, S. (1981). The amnesic H.M.: Leaming and retention of perceptual skills. Society for Neurosciences Abstracts, 7, 235.

Poulos, C. X., Wilkinson, D. A. (1984). A process theory of remembering: Its application to Korsakoff amnesia and a critique of context and episodic-semantic theories. In L. S. Squire \& N. Butters (Eds.), Neuropsychology of memory (pp. 67-82). New York: Guilford.

Rappold, V. A., Hashtroud, S. (1991). Does organization improve priming? Journal of Experimental Psychology: Learning, Memory, \& Cognition, 17, 103-114.

Richardon-Klavehn, A., Bjork, R. A. (1988). Measures of memory. Annual Review of Psychology, 39, 475-543.

RoEDIGER, H. L., III (1990). Implicit memory: Retention without remembering. American Psychologist, 45, $1043-1056$.

Roediger, H. L., III, \& BLAXTON, T. A. (1987a). Effects of varying modality, surface features, and retention interval on priming in wordfragment completion. Memory \& Cognition, 15, 379-388.

Roediger, H. L., III, \& Blaxton, T. A. (1987b). Retrieval modes produce dissociations in memory for surface information. In $D$. $S$. Gorfein \& R. R. Hoffman (Eds.), Memory and learning: The Ebbinghaus Centennial Conference (pp. 349-379). Hillsdale, NJ: Erlbaum.

Roediger, H. L., III, Srinivas, K., \& Weldon, M. S. (1989). Dissociations between implicit measures of retention. In $\mathrm{S}$. Lewandowsky, J. C. Dunn, \& K. Kirsner (Eds.), Implicit memory: Theoretical issues (pp. 67-84). Hillsdale, NJ: Erlbaum.

Roediger, H. L., III, Weldon, M. S., Challis, B. H. (1989). Explaining dissociations between implicit and explicit measures of retention: A processing account. In H. L. Roediger III \& F. I. M. Craik (Eds.), Varieties of memory and consciousness: Essays in honour of Endel Tulving (pp. 3-41). Hillsdale, NJ: Erlbaum.

Schacter, D. L. (1985). Priming of old and new knowledge in amnesic patients and normal subjects. In D. S. Olton, E. Gamzu, \& S. Corkin (Eds.), Memory dysfunctions: An integration of animal and human research from preclinical and clinical perspectives. Annals of the New York Academy of Sciences, 444, 41-53.

SCHACTER, D. L. (1987). Implicit memory: History and current status. Journal of Experimental Psychology: Learning, Memory, \& Cognition, 13, 501-518.

SChacter, D. L. (1991). Perceptual representation systems and im- 
plicit memory: Toward a resolution of the multiple memory systems debate. In A. Diamond (Ed.), Development and neural bases of higher cognitive function. Annals of the New York Academy of Sciences, 608, 543-571.

SCHACTER, D. L., Bowers, J., \& BoOKer, J. (1989). Intention, awareness, and implicit memory: The retrieval intentionality criterion. In S. Lewandowsky, J. C. Dunn, \& K. Kirsner (Eds.), Implicit memory: Theoretical issues (pp. 47-65). Hillsdale, NJ: Erlbaum.

Schacter, D. L., \& GraF, P. (1986a). Effects of elaborative processing on implicit and explicit memory for new associations. Jourmal of Experimental Psychology: Learning, Memory, \& Cognition, 12, $432-444$.

Schacter, D. L., \& Graf, P. (1986b). Preserved learning in amnesic patients: Perspectives from research on direct priming. Journal of Clinical \& Experimental Neuropsychology, 8, 727-743.

Shimamura, A. P. (1986). Priming effects in amnesia: Evidence for a dissociable memory function. Quarterly Joumal of Experimental Psychology, 38A, 619-644.

Shimamura, A. P., \& Squire, L. R. (1984). Paired-associate learning and priming effects in amnesia: A neuropsychological approach. Journal of Experimental Psychology: General, 113, 556-570.

Shimamura, A. P., \& SQuire, L. R. (1989). Impaired priming of new associations in amnesia. Journal of Experimental Psychology: Learning, Memory, \& Cognition, 15, 721-728.

Smith, D. B. (1987). Anticonvulsants, seizures and performance: The Veteran's Administrative experience. In M. R. Trimble \& E. H. Reynolds (Eds.), Epilepsy, behavior, and cognitive function (pp. 67-83). New York: Wiley.

SQuire, L. S. (1987). Memory and brain. New York: Oxford University. SQuire, L. S., WeTZEL, C. D., \& Slater, P. C. (1978). Anterograde amnesia following ECT: An analysis of the beneficial effect of partial information. Neuropsychologia, 16, 339-347.

Srinivas, K., \& Roediger, H. L., III (1990). Testing the nature of two implicit tests: Dissociations between conceptually driven and datadriven processes. Journal of Memory \& Language, 29, 389-412.

Tulving, E., \& Donaldson, W. (1972). Organization of memory. San Diego, CA: Academic Press.
Tulving, E., \& SCHACter, D. L. (1990). Priming and human memory systems. Science, 247, 301-306.

Warrington, E. K., \& Weiskrantz, L. (1968). New method of testing long-term retention with special reference to amnesic patients. Nature, 217, 972-974.

WarRington, E. K., \& Weiskrantz, L. (1970). Amnesic syndrome: Consolidation or retrieval? Nature, 228, 628-630.

WeISKRANTZ, L. (1985). On issues and theories of the human amnesic syndrome. In N. M. Weinberger, J. L. McGaugh, \& G. Lynch (Eds.), Memory systems of the brain (pp. 380-415). New York: Guilford.

WeLDon, M. S., \& Roediger, H. L., III (1987). Altering retrieval demands reverses the picture superiority effect. Memory \& Cognition, 15, 269-280.

Wood, F., Ebert, V., \& Kinsbourne, M. (1982). The episodicsemantic memory distinction in memory and amnesia: Clinical and experimental observations. In L. S. Cermak (Ed.), Human memory and amnesia (pp. 167-193). Hillsdale, NJ: Erlbaum.

\section{NOTES}

1. Researchers studying cognition in epileptic patients usually do not match them to normal subjects on the basis of WAIS-R or other IQ scores. It is widely accepted that the anticonvulsant medications administered to epileptic patients have specific effects on particular cognitive functions, including sustained attention and motor manipulation (e.g., Smith, 1987). These effects impact heavily on certain subtasks of standardized tests, yielding lowered overall scores. Thus, if patients and normal subjects in memory studies were equated on the basis of IQ scores, the normals would likely be functioning at lower levels than would the patients on dimensions of interest in this research area.

2. The fact that transfer was normal on the (verbal) word-fragment and graphemic cued-recall tests for impaired subjects in Experiments 1 and 2 is further evidence against the notion that these patients suffer from generic verbal deficits.

(Manuscript received September 25, 1990; revision accepted for publication December 23, 1991.) 